\section{Islamic Mathematics 1}

T he period from 750 to $1400 \mathrm{AD}$ was an important time for the development of mathematics. United by their new religion, Islamic scholars seized on Classical works from the west and Hindu works from the east, wrote extensive commentaries on them, and developed them.

Several mathematical terms date from this time. The word algorithm derives from Muhammad ibn Musa alKhwarizmi (c.750-850), a Persian mathematician who wrote influential works on arithmetic and algebra. His Arithmetic helped to introduce the Hindu decimal place-value number system to the Islamic world, and the title of his algebra book, Kitab al-jabr wal-muqabala gives us the term algebra; al-jabr refers to transposing a term from one side of an algebraic equation to the other.

Al-Biruni (973-1055) was an outstanding intellectual figure who wrote more than 140 works, primarily on mathematics, astronomy, geography, and the calendar. He was one of the first mathematicians to investigate the tangent, cotangent, secant, and cosecant functions.

Ibn al-Haitham (965-1039), known in the west as Alhazen, was a geometer whose main contributions were to the study of optics. A celebrated problem is "Alhazen's problem": where, on a spherical mirror, is light from a given point source reflected into the eye of a given observer (or where, on the cushion of a circular billiard table, must a cue ball be aimed so as to hit a given target ball)?

Omar Khayyam (1048-1131) was a mathematician and poet who wrote a major algebra text with the first systematic classification of cubic equations and discussion of their solution; they were not to be solved in general until the 16th century. He is known in the west mainly for his collection of poems known as the Rubaiyat. Omar Khayyam publicly criticised an attempted proof by al-Haitham of Euclid's so-called "parallel postulate."

A later unsuccessful attempt to prove this postulate was provided by the Persian mathematician Nasir al-din al-Tusi (1201-1274). Al-Tusi wrote substantial works on astronomy and constructed the first modern observatory. He also wrote influential treatises on logic, theology, and ethics, and his extensive investigations into plane and spherical trigonometry included the sine rule for triangles

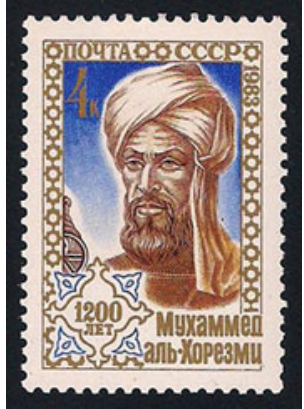

\section{Al-Khwarizmi}

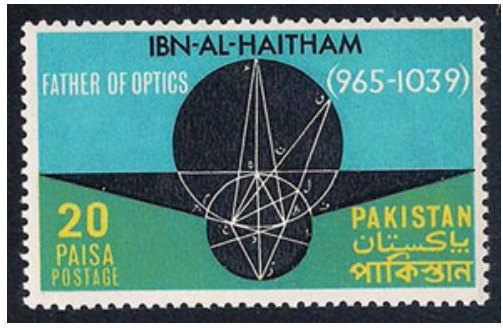

Alhazen's geometry

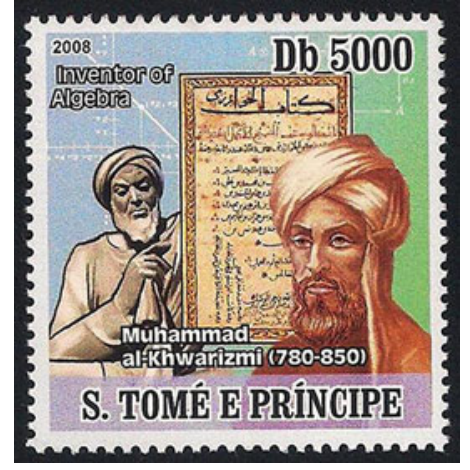

\section{Al-Khwarizmi's Algebra}

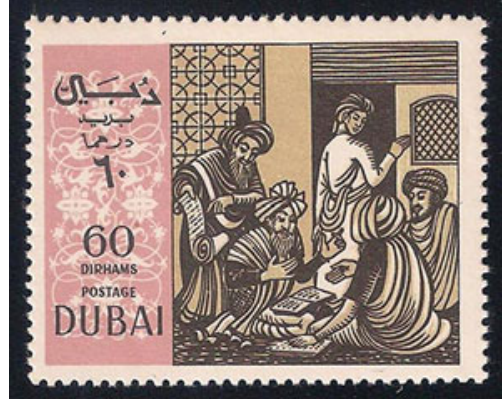

Omar Khayyam's Rubaiyat

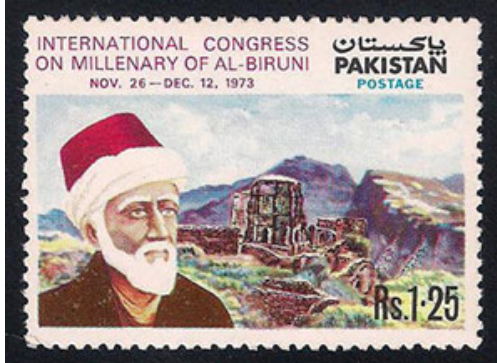

Al-Biruni

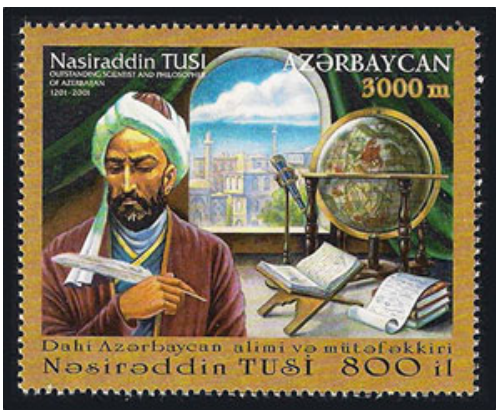

Al-Tusi

> Robin Wilson, Pembroke College,

Oxford, OXI IDW, UK

e-mail: r.j.wilson@open.ac.uk 